\title{
Ring dermoid of cornea
}

INSERM

\section{Source}

INSERM. (1999). Orphanet: an online rare disease and orphan drug data base. Ring dermoid of cornea. ORPHA:91481

Ring dermoid of cornea is characterised by annular limbal dermoids (growths with a skinlike structure) with corneal and conjunctival extension. Less than 30 cases have been described. Transmission is autosomal dominant and mutations in the PITX2 gene have been suggested as a potential cause of the condition. 